\title{
APAP titration in patients with mild to moderate OSAS and periodic limb movement syndrome
}

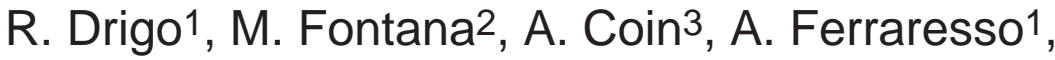 \\ E. Enzo' ${ }^{1}$ F.M. Zambotto ${ }^{1}$
}

ABSTRACT: APAP titration in patients with mild to moderate OSAS and periodic limb movement syndrome. R. Drigo, M. Fontana, A. Coin, A. Ferraresso, E. Enzo, F.M. Zambotto.

Aims. 1) to evaluate automatic positive airway pressure (APAP) titration in a partially attended setting; 2 ) to verify whether APAP performance depends on the apneahypopnea and periodic limb movement indexes (PLMI).

Methods. 65 CPAP naïve subjects with a sleep disorder of breathing and daytime sleepiness underwent a standard polysomnography (first night), APAP titration (second night, partially attended), and a standard polysomnography using continuous positive airway pressure (CPAP) at the effective pressure $\left(P_{\text {eff }}\right)$ established from the APAP titration (third night) in a sleep disorder laboratory in a 400-bed community hospital. We examined the apnea-hypopnea index (AHI), sleep stages, arousals induced by respiratory events (RESPa) and PLM (PLMa), and oxygen saturation during the first and third nights on CPAP at the $P_{\text {eff }}$ Patients were divided into three groups according to their AHI and PLMI.

Results. At the $\mathbf{P}_{\text {eff }}$ defined using APAP on the third night, the mean AHI dropped from $29.6 \pm 21.8$ to $3.1 \pm 3.4$, and the RESPa index from $16.5 \pm 16.2$ to $1.7 \pm 2.6$. No differences emerged in sleep stages or spontaneous arousals (first vs third night). Overall, $92 \%$ of the patients met the standard for an acceptable outcome of positive pressure titration. Baseline AHI and PLMI did not affect the outcome of titration.

Conclusions. In patients with mild to moderate OSAS and PLMS, APAP titration enables the optimal fixed pressure for CPAP home therapy to be determined in at least $90 \%$ of patients.

Monaldi Arch Chest Dis 2006; 65: 4, 196-203.

Keywords: CPAP, titration, OSAS, periodic limb movements.

1 U.O.A. Pneumologia, Ospedale di Feltre (BL), ULSS 2,

2 U.O.A. Pneumologia, Ospedale di Cittadella (PD), ULSS 15,

3 Clinica Geriatrica, Dipartimento di Scienze Mediche e Chirurgiche, Università di Padova, Italy.

Correspondence: Alessandra Coin; Clinica Geriatrica, Ospedale Giustinianeo; Via Giustiniani 2, 35128 Padova, Italy; e-mail: alessandra.coin@unipd.it

\section{Introduction}

Obstructive sleep apnea syndrome (OSAS) is a disorder affecting 2-4\% of the adult population [1]. Nasal continuous positive airway pressure (CPAP) is the treatment of choice for patients with moderate to severe OSAS [2-4]. The pressure to be used in home treatment is usually determined during an attended polysomnography at the sleep laboratory. This conventional approach has many advantages, enabling the technician to adjust the pressure according to the patient's needs and check for problems with the mask and leaks, but it is costly and gives rise to long waiting lists.

Other ways to find the optimal pressure for CPAP therapy have consequently been suggested: split night studies [5], prediction formulae [6], patient and bed-partner reports [7], and limited unattended or attended portable monitoring [8].

Auto-titrating continuous positive airway pressure (APAP) devices have also been proposed to ensure an optimal level of CPAP in attended and unattended settings [9]. The American Academy of Sleep Medicine stated that certain APAP de- vices can be used during attended titration to identify a single pressure for use with standard CPAP by polysomnography; it also said that the use of unattended APAP titration is not yet well established and further studies are needed [10]. In fact, some important questions remain unanswered from a clinical point of view:

1. There are numerous different APAP devices and only a few have been tested: findings with one device cannot be extrapolated to others [10].

2. Some authors obtained poor results when APAP devices were used to select a fixed pressure [11-13].

3. Any influence of underlying conditions, such as PLM, on APAP titration remains to be seen.

4. No studies have specifically evaluated the effectiveness of APAP in patients with Upper Airway Resistance Syndrome or mild OSAS [10].

5. The value of unattended APAP titration has yet to be established [10].

To our knowledge, the Goodknight 418P (manufactured by Tyco), which is a device responding to apnea, hypopnea, snoring and flow 
limitation, has never been tested for APAP titration in a clinical setting.

Our objectives in this study were twofold:

1. To evaluate a hitherto-untested device during partially attended APAP titration in CPAPnaïve patients; and

2. To verify whether APAP performance depends on baseline AHI and PLMI.

\section{Methods}

\section{Patients}

The sample population consisted of 65 subjects (51 males, 14 females) consecutively referred to the Sleep Lab of Feltre City Hospital for sleepdisordered breathing (SDB), who met the following criteria:

1. Clinical symptoms suggestive of OSAS, with at least snoring and excessive daytime sleepiness (Epworth Sleepiness Scale [ESS] score >10).

2. No history of stroke or heart failure. Patients with daytime respiratory failure, neuromuscular disease, nasal obstruction, or chronic obstructive pulmonary disease were excluded, as were patients with central sleep apnea and periodic breathing.

3. Standard polysomnography suggestive of SDB; and

4. CPAP-naïve.

Informed consent was obtained, and the protocol was approved by the Hospital Ethics Committee.

There was no financial support from the manufacturer.

\section{APAP device}

The Goodknight 418P uses a pneumotachograph to detect flow limitations, snoring, hypopnea and apnea and increases the pressure in response to these events.

If the monitoring algorithm detects no breath for at least 10 seconds plus $5 / 8$ of the mean breath time, this is read as an apnea. Algorithms attempt to classify each apnea as obstructive or central: if cardiac oscillations are detected, the apnea is classified as central (apnea with open airway) and the response algorithm disregards it; if no cardiac oscillations are detected, the apnea is classified as obstructive and the pressure is increased.

If the monitoring algorithm detects a $<40 \%$ decrease in the average amplitude of the last 8 breaths lasting 10 seconds, this is considered hypopnea. Snoring is measured from the filtered flow signal.

The monitoring algorithm also detects changes in the inspiratory flow-time curve suggestive of inspiratory flow limitation (plateau) [14]. According to any plateau and/or snoring on the inspiratory flow-time curve, each breath is classified as normal (no flow limitation, sinusoidal shape), intermediate (mild flow limitation) or flow-limited (moderate to severe flow limitation). A period of flow limitations is defined as a "run". A "run" is detected after two respiratory cycles defined as flow-limited, or after 10 breathing cycles defined as "intermediate".

Apnea, hypopnea and snoring make the APAP pressure increase by 1 or $0.5 \mathrm{~cm}$ of a column of water $\left(\mathrm{cm} \mathrm{H}_{2} \mathrm{O}\right)$. Runs of flow limitation prompt a pre-set increase in APAP pressure (setting options: $0.1,0.2$, or $0.3 \mathrm{~cm} \mathrm{H}_{2} \mathrm{O}$ ).

If no events are detected for 5 minutes the APAP pressure decreases by $0.5 \mathrm{~cm} \mathrm{H}_{2} \mathrm{O}$ every 5 minutes.

\section{Sleep studies}

Sleep studies were scored in accordance with the Rechtschaffen and Kales guidelines [15]. We recorded the EEG (C3A2, O2A1), submental and bilateral anterior tibialis electromyogram, electrooculogram, electrocardiogram. Flow was recorded using both a nasal cannula [16] (Protech Minneapolis $\mathrm{MN}$ ) and thermistors, without using square correction of the nasal cannula signal [17].

During CPAP, the mask replaced the nasal cannula. Thoraco-abdominal movements were recorded by piezoelectric bands, and arterial oxygenation by a pulse oximeter (finger probe) set at a 4-second averaging time (Nellcor, Hayward, CA) [18]. For breathing noises, we used a microphone placed on the anterior neck. The position during sleep and pressure level during CPAP in the mask were also recorded. All data was recorded using a computerassisted system (Grass Telefactor, W. WarvicK RI).

Polysomnography was scored manually using the following criteria: obstructive apnea was identified as an episode of absent flow on the thermistor and nasal cannula lasting $>10 \mathrm{~s}$, with associated chest wall and abdomen movements; hypopnea was scored according to the American Academy of Sleep Medicine criteria (a clearly reduced signal from the nasal cannula lasting $10 \mathrm{~s}$ or longer, associated with oxygen desaturation $>3 \%$ or arousal) [19]. Apneas and hypopneas were combined to define the apnea-hypopnea index (AHI).

Arousal and PLM were scored using the American Sleep Disorder Association criteria [20]. Bursts of delta waves or K complex were also included as arousals if they were clearly associated with breathing or PLM events [21]. Arousals associated with apneas and hypopneas were defined as "respiratory arousals" (RESPa), while those associated with PLM were defined as "PLM arousals" (PLMa). Arousals associated with both PLM and the end of a breathing event was classified as RESPa. The RESPa index (RESPaI) and PLMa index (PLMaI) were calculated. Arousals associated with neither of the afore-mentioned events were classified as "spontaneous arousals" (SPONTa).

\section{Titration protocol}

On the first night, patients underwent conventional polysomnographic recordings to confirm their sleep-related breathing disorder, placing the thermistor only at the mouth. When a mouth flow was recorded for more than $50 \%$ of the first night, the patient was considered as a mouth breather, and 
a full face mask was the first choice for the titration.

On the afternoon of the second day, patients were adapted to CPAP while awake, using a fixed low pressure $\left(5 \mathrm{~cm} \mathrm{H}_{2} \mathrm{O}\right)$. Patients refusing CPAP adaptation were excluded.

During the night, autotitration was performed in a conventional hospital room beginning with a pressure of $4 \mathrm{~cm} \mathrm{H}_{2} \mathrm{O}$. The device was allowed to work within a pressure range of $5-15 \mathrm{~cm} \mathrm{H}_{2} \mathrm{O}$.

The pressure increase for apnea, hypopnea and snoring was set at $1 \mathrm{~cm} \mathrm{H}_{2} \mathrm{O}$, while for runs of flow limitation it was set at $0.1 \mathrm{~cm} \mathrm{H}_{2} \mathrm{O}$. Patients were prepared by a nurse. During the night, nurses were allowed to intervene only at the patient's request. No monitors were used. Problems occurring during the titration were described in the nurse's night report.

On the following morning, three of the Authors analysed the printed summary reports. After excluding recording periods when mask leaks exceeded $0.4 \mathrm{l} / \mathrm{s}$, and any other unusual temporary pressure increases, the $95^{\text {th }}$ percentile pressure (i.e. the pressure level during $95 \%$ of the study period) was selected as the optimal pressure for CPAP $\left(\mathrm{P}_{\mathrm{eff}}\right)$ [10]. If patients complained of "too much air", or "too much pressure in the nose" during the night, the $\mathrm{P}_{\text {eff }}$ was lowered by $1 \mathrm{~cm} \mathrm{H}_{2} \mathrm{O}$. A second study was conducted the next night if mask leaks affected $>20 \%$ of the report.

On the third night, patients underwent conventional polysomnography at the $\mathrm{P}_{\text {eff }}$ delivered by a fixed pressure CPAP device. Patients received no heated humidity on CPAP.

\section{Statistical analysis}

Data was analysed with the Systat statistical software for Windows, rel. 11.05 (SPSS Inc. Chicago), expressing results as mean \pm standard deviation and frequency percentage. Differences in variables between groups were evaluated by Student's paired two-sided $t$-test for normal distributions and the Kruskal-Wallis test for non-normal distributions.
The level of statistical significance for each test was set as $<0.05$.

\section{Results}

The patients' mean age was $54.3 \pm 10.8$ and their mean body mass index was $30.3 \pm 4.8$. Their mean ESS score was $12.5 \pm 1.8$.

Seven patients with AHI $<10$ and 4 with AHI $<5$, and presenting both daytime sleepiness (ESS $>13$ ) and polysomnographic features of above-normal upper airway resistance (snoring, frequent runs of inspiratory flow limitation with respiratory arousals, out of phase movements of respiratory bands) were suspected of having an upper airway resistance syndrome and offered a CPAP trial.

Two patients refused the CPAP adaptation on the afternoon of the second day. None refused APAP during titration.

APAP titration had to be repeated in ten patients due to frequent mask leaks (>20\% of the report).

Table 1 shows the polysomnographic findings at the baseline and during the third night on CPAP at the $\mathrm{P}_{\text {eff. }}$. There were significant reductions in AHI and respiratory arousals after CPAP therapy. No differences emerged in sleep stages, spontaneous arousals, PLMI or PLMaI.

Tables 2 and 3 show the outcome of CPAP at $\mathrm{P}_{\text {eff }}$ vis-à-vis baseline AHI and PLMI.

The mean $\mathrm{P}_{\text {eff }} \pm \mathrm{SD}$ was $10 \pm 3 \mathrm{~cm} \mathrm{H}_{2} \mathrm{O}$. There were no significant differences between the groups for the various parameters considered in Table 2, while significant differences emerged for PLMI and PLMaI (Table 3).

Table 4 shows the level of control obtained

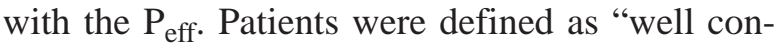
trolled" when the AHI was $\leq 5$, "controlled" when the AHI was $\leq 10$ but $>5$, and not controlled when it was $>10$. Subjects with a baseline AHI $<5$ were excluded from "well controlled" patients and subjects with baseline AHI $<10$ were excluded from "controlled" patients (totaling 11 patients).

Table 1. - Sleep architecture parameters: baseline and during third night on CPAP at $\mathrm{P}_{\text {eff }}$ (expressed as mean \pm standard deviation)

\begin{tabular}{lccc}
\hline & Baseline & CPAP & p \\
\hline AHI & $29.6 \pm 21.8$ & $3.1 \pm 3.4$ & 0.000 \\
ODI & $20.3 \pm 18.8$ & $1.2 \pm 2.2$ & 0.000 \\
SPONTaI & $8.5 \pm 7$ & $9.8 \pm 9.4$ & $\mathrm{~ns}$ \\
RESPaI & $16.5 \pm 16.2$ & $1.7 \pm 2.6$ & 0.000 \\
PLMaI & $4.1 \pm 10.8$ & $3.6 \pm 7.3$ & $\mathrm{~ns}$ \\
PLMI & $14 \pm 18.3$ & $9.8 \pm 16$ & 0.01 \\
TST & $297.9 \pm 40.9$ & $282.5 \pm 42.9$ & 0.03 \\
REM\% & $17.3 \pm 7.4$ & $17.3 \pm 6.8$ & $\mathrm{~ns}$ \\
$\mathrm{BACK} \%$ & $22.7 \pm 7.8$ & $23.8 \pm 8.5$ & 0.06 \\
$\mathrm{SpO}_{2}$ & $93.9 \pm 1.3$ & $94.8 \pm 1.8$ & $\mathrm{~ns}$ \\
\hline
\end{tabular}

AHI: apnea-hypopnea index ( $\mathrm{n}^{\circ}$ events/hour); ODI: oxygen desaturation index $\left(\mathrm{n}^{\circ}\right.$ desaturations $>4 \% /$ hour$)$; SPONTaI: spontaneous arousal index ( ${ }^{\circ}$ events/hour); RESPaI: respiratory arousal index ( $n^{\circ}$ events/hour); PLMaI: periodic limb movement arousal index ( $\mathrm{n}^{\circ}$ events/hour); TST: total sleep time (minutes); REM\%: \% of TST in REM stage; BACK\%: \% of TST in back position; $\mathrm{SpO}_{2}$ : oxygen saturation (in \%); p: statistical significance; ns: not statistically significant. 
Table 2. - AHI during the third night on CPAP at $\mathrm{P}_{\text {eff }}$ in patients with different $\mathrm{AHI}$ at the baseline (values expressed as mean \pm standard deviation)

\begin{tabular}{|c|c|c|c|}
\hline & $\begin{array}{c}\text { Group 1 } \\
\text { AHI^ }^{\wedge} \leq 15\end{array}$ & $\begin{array}{c}\text { Group } 2 \\
15<\text { AHI }^{\wedge} \leq 30\end{array}$ & $\begin{array}{c}\text { Group } 3 \\
\text { AHI^ }^{\wedge} \mathbf{3 0}\end{array}$ \\
\hline $\mathrm{N}^{\circ} \mathrm{pt}$ & 15 & 24 & 26 \\
\hline$A H I^{\wedge}$ & $6.6 \pm 3.6$ & $22.9 \pm 3.4$ & $49.0 \pm 21.2$ \\
\hline$P L M I^{\wedge}$ & $14.2 \pm 17.3$ & $10.1 \pm 13.0$ & $17.5 \pm 22.4$ \\
\hline AHI & $3.2 \pm 3.1$ & $2.8 \pm 3.7$ & $3.2 \pm 3.4$ \\
\hline ODI & $1.5 \pm 1.8$ & $1.3 \pm 2.1$ & $1.9 \pm 2.9$ \\
\hline SPONTaI & $6.6 \pm 6.1$ & $9.0 \pm 7.3$ & $12.3 \pm 11.9$ \\
\hline RESPaI & $1.2 \pm 2.2$ & $2.0 \pm 3.0$ & $1.6 \pm 2.3$ \\
\hline PLMaI & $3.6 \pm 6.6$ & $2.9 \pm 6.8$ & $4.4 \pm 8.2$ \\
\hline PLMI & $11.2 \pm 14.1$ & $7.0 \pm 11.9$ & $11.6 \pm 20.0$ \\
\hline TST & $298.7 \pm 31.3$ & $281.5 \pm 41.1$ & $274.2 \pm 48.8$ \\
\hline REM\% & $15.3 \pm 8.6$ & $18.9 \pm 5.5$ & $17.1 \pm 6.7$ \\
\hline BACK & $23.5 \pm 5.5$ & $21.8 \pm 4.9$ & $19.6 \pm 3.1$ \\
\hline $\mathrm{SpO}_{2}$ & $95.1 \pm 2.1$ & $94.9 \pm 1.9$ & $94.3 \pm 1.8$ \\
\hline
\end{tabular}

^: baseline values; $\mathrm{N}^{\circ}$ pt: number of patients; AHI: apnea-hypopnea index ( $\mathrm{n}^{\circ}$ events/hour); SPONTaI: spontaneous arousal in$\operatorname{dex}\left(\mathrm{n}^{\circ}\right.$ events/hour); RESPaI: respiratory arousal index ( $\mathrm{n}^{\circ}$ events/hour); PLMaI: periodic limb movement arousal index $\left(\mathrm{n}^{\circ}\right.$ events/hour); PLMI: periodic limb movements index ( $\mathrm{n}^{\circ}$ events/hour); TST: total sleep time (minutes); REM\%: \% of TST in REM stage; $\mathrm{BACK} \%$ : \% of TST in back position; $\mathrm{SpO}_{2}$ : oxygen saturation (in \%).

No statistical significance was found.

Table 3. - AHI during the third night on CPAP at $\mathrm{P}_{\text {eff }}$ in patients with different PLMI at the baseline (values expressed as mean \pm standard deviation)

\begin{tabular}{|c|c|c|c|}
\hline & $\begin{array}{c}\text { Group } 1 \\
\text { PLMI^ } \leq 5^{-1}\end{array}$ & $\begin{array}{c}\text { Group 2 } \\
5<\text { PLMI }^{\wedge} \leq 25\end{array}$ & $\begin{array}{c}\text { Group } 3 \\
\text { PLMI^ }^{\wedge}>25\end{array}$ \\
\hline $\mathrm{N}^{\circ} \mathrm{pt}$ & 28 & 28 & 9 \\
\hline$P L M I^{\wedge}$ & $0.9 \pm 1.6$ & $14.8 \pm 6.2$ & $52.3 \pm 17$ \\
\hline$A H I^{\wedge}$ & $26.0 \pm 20.4$ & $32.3 \pm 22.5$ & $32.2 \pm 24.8$ \\
\hline AHI & $3.5 \pm 3.8$ & $2.9 \pm 3.4$ & $2.2 \pm 2$ \\
\hline ODI & $1.5 \pm 2.1$ & $2.1 \pm 1.9$ & $1.1 \pm 1.5$ \\
\hline SPONTaI & $11.1 \pm 10$ & $7.8 \pm 6.1$ & $11.9 \pm 14.8$ \\
\hline RESPaI & $1.8 \pm 2.9$ & $1.9 \pm 2.6$ & $0.6 \pm 1$ \\
\hline PLMaI & $0.5 \pm 1.3$ & $5 \pm 9.2 *$ & $9.2 \pm 7.5 \#$ \\
\hline PLMI & $1.8 \pm 4.1$ & $10.5 \pm 12.8 *$ & $32.7 \pm 25.2$ \\
\hline TST & $287.2 \pm 39$ & $274.3 \pm 51.1$ & $293.7 \pm 18.8$ \\
\hline REM\% & $17 \pm 7.2$ & $16.9 \pm 6.7$ & $19.8 \pm 5.6$ \\
\hline BACK & $22.5 \pm 5.1$ & $21.9 \pm 3.9$ & $19.4 \pm 3.4$ \\
\hline $\mathrm{SpO} 2$ & $95.3 \pm 2.3$ & $94.8 \pm 1.7$ & $94.1 \pm 1.6$ \\
\hline
\end{tabular}

p: statistical significance; *: p < 0.001 between group 2 and group 1; \#: $p<0.001$ between group 3 and group 2; ^: baseline values; $\mathrm{N}^{\circ}$ pt: number of patients; AHI: apnea-hypopnea index ( ${ }^{\circ}$ events/hour); SPONTaI: spontaneous arousal index ( $\mathrm{n}^{\circ}$ events/ hour); RESPaI: respiratory arousal index ( $\mathrm{n}^{\circ}$ events/hour); PLMaI: periodic limb movement arousal index $\left(\mathrm{n}^{\circ}\right.$ events/hour); PLMI: periodic limb movements index ( ${ }^{\circ}$ events/hour); TST: total sleep time (minutes); REM\%: \% of TST in REM stage; BACK\%: \% of TST in back position; SpO2: oxygen saturation (in \%).

Table 4. - Effect of CPAP at $\mathrm{P}_{\text {eff, }}$, based on $\mathrm{AHI}$ as outcome

\begin{tabular}{|c|c|}
\hline & $\mathbf{N}^{\circ} \mathbf{p t}$ \\
\hline $\mathrm{AHI} \leq 5$ & $39(72.2 \%) \mathrm{wc}$ \\
\hline $5<\mathrm{AHI} \leq 10$ & $11(20.3 \%) \mathrm{c}$ \\
\hline $\mathrm{AHI}>10$ & $4(7.5 \%) \quad \mathrm{nc}$ \\
\hline
\end{tabular}

AHI: apnea-hypopnea index ( $\mathrm{n}^{\circ}$ events/hour); $\mathrm{N}^{\circ} \mathrm{pt}$ : number of patients; ( ): \% of total of patients; wc: well controlled; c: controlled; nc: not controlled.
"Controlled" and "well controlled" patients accounted for $92 \%$ of patients (50/54) meeting historical standards for an acceptable outcome of positive pressure titration i.e. an AHI <10 [10].

Table 5 shows baseline and CPAP data for the 4 patients whose disorder was "not controlled". By comparison with the baseline values, however, the AHI values recorded after CPAP therapy were acceptable.

Titration was repeated in 5 patients due to frequent leaks. During more than $80 \%$ of the titration nights, the nurses were asked to intervene once or more: the most common problems were air leaks, 
Table 5. - Polysomnographic variables at baseline and during nasal CPAP in 4 patients whose condition was not controlled at $\mathrm{P}_{\text {eff }}$

\begin{tabular}{lcccccccc}
\hline & \multicolumn{3}{c}{ BASELINE VALUES } & \multicolumn{3}{c}{ CPAP VALUES } \\
\hline & AHI & RESPaI & PLMI & PLMaI & AHI & RESPaI & PLMI & PLMaI \\
\hline Patient n $^{\circ}$ 1 & 23.5 & 18.7 & 5.2 & 0 & 10.2 & 7.8 & 6.9 & 3.1 \\
Patient n $^{\circ}$ 2 & 20.5 & 15.1 & 2.9 & 0 & 11.6 & 8.5 & 1.8 & 0.2 \\
Patient $^{\circ}$ 3 & 38.1 & 13.5 & 1.4 & 0 & 13.5 & 10 & 9.2 & 1.8 \\
Patient $^{\circ}{ }^{\circ}$ 4 & 21.9 & 7.2 & 15.6 & 2.3 & 12.6 & 9 & 13.1 & 4.1 \\
\hline
\end{tabular}

AHI: apnea-hypopnea index ( ${ }^{\circ}$ events/hour); RESPaI: respiratory arousal index ( ${ }^{\circ}$ events/hour); PLMaI: periodic limb movement arousal index ( $\mathrm{n}^{\circ}$ events/hour); PLMI: periodic limb movements index ( $\mathrm{n}^{\circ}$ events/hour).

discomfort with the mask, and the pressure being "too high" or the air "too cold".

\section{Discussion}

Our aims were to evaluate whether the $\mathrm{P}_{\text {eff }}$ determined with the APAP device can prevent apneas and hypopneas and whether APAP performance depends on baseline AHI and PLMI.

Our results suggest that the tested APAP device determines an effective fixed pressure in more than $90 \%$ of patients, irrespective of baseline AHI and PLMI.

Six randomised controlled trials [12, 22-26] and five clinical series [11,27-30] used attended or unattended APAP titration to determine a $\mathrm{P}_{\text {eff }}$ and most of them found APAP titration suitable for selecting a fixed CPAP pressure to reduce the AHI to $<10$ in $80-90 \%$ of OSAS patients. Most patients had moderate to severe OSAS. Pressures from manual and APAP titration were usually within 1 or $2 \mathrm{~cm} \mathrm{H}_{2} \mathrm{O}$. The number of the technician's interventions and problems during APAP titration were not always extensively reported.

Not all these studies report positive results.

Fletcher [11] reported $22 \%$ of unsatisfactory titrations in patients undergoing unattended APAP titration/treatment.

In some patients, there were considerable differences between CPAP and APAP pressure levels [12, 26]. Devices based on different technologies could predict significantly different therapeutic pressures in the same patients [13]; moreover, APAP technologies based on flow limitation [9] and poor sleep quality during autotitration [31] could lead to an undesirable overestimation of the $\mathrm{P}_{\mathrm{eff}}$.

Most of the previous studies used the AutoSet T (ResMed, North Ryde, Australia) for APAP titration. An earlier model of the Goodknight (the 420A) was tested only to detect upper airway obstruction [32]. To our knowledge, the 418P had never been tested for APAP titration.

Our findings suggest a good overall performance of the device: the $\mathrm{P}_{\text {eff }}$ was effective in more than $90 \%$ of patients, while in the 4 cases that were "not controlled", the AHI was very near to 10, and the RESPa index was $<10$ in all but one.

In four patients, APAP failed to identify a therapeutic pressure: during the third night at the
APAP-fixed CPAP pressure, they still had an AHI $>10$ (table 5)

Patient $\mathrm{n}^{\circ} 4$ had PLM in the baseline study and during CPAP, and these PLM may have played a role in the failure of APAP titration (see below).

Patient $n^{\circ} 2$ had a cyclic alternating pattern (CAP) and CAP-dominant obstructive sleep-disordered breathing (CAP rate $81 \%$, AHI during nonREM sleep higher than AHI during REM sleep, i.e. 27 vs 2). Standard titration is reported difficult in such patients and this is probably true of APAP titration too [33].

We have no explanations for the other two cases in which APAP titration failed.

It has been reported [24] that APAP devices attempting to normalise upper airway flow limitation may overestimate the $\mathrm{P}_{\text {eff }}$, because higher pressures are needed to eliminate residual snoring and respiratory effort-related arousals associated with airflow limitation. We do not know whether this is true of the 418P, because we did not compare APAP titration with conventional manual titration.

The $\mathrm{P}_{\text {eff }}$ used during the night on CPAP was nonetheless generally well tolerated and none of the patients refused the treatment.

Nurses frequently had to intervene: about $80 \%$ of patients called them at least twice, suggesting that single-night APAP titration is best performed in a setting enabling a nurse's intervention, rather than unattended at home. Partially-attended APAP titration in a medical ward (not necessarily a sleep laboratory) would seem to be a reasonable alternative.

We examined a wide range of SDB, comparing APAP in patients with different AHI. Most papers on APAP titration have studied patients with moderate to severe AHI, while little is known about APAP titration in patients with AHI $<30$ and sleepiness.

Table 2 shows that, at the APAP-fixed $\mathrm{P}_{\text {eff }}$, the AHI was the same in patients with different baseline AHI. Our results suggest that the device performs equally well in a wide range of SDB.

PLM are brief, stereotyped, repetitive movements of one or both lower limbs occurring with a remarkable periodicity, primarily during non-REM sleep. Many patients with OSAS have PLM, and they do not always improve during CPAP treatment [34, 35].

No papers to date have reported on PLM and APAP titration. If APAP titration is "disturbed" by PLM, this would be a major drawback for clinical 
purposes. In theory, PLM may interfere with APAP titration in two ways. Firstly, they may be associated with electroencephalographic arousals and sleep fragmentation [36]. In addition, poor sleep quality during an autotitration night could lead to an undesirable overestimation of the $\mathrm{P}_{\text {eff }}$ [31]. If PLM are associated with poor sleep quality irrespective of any apneas and hypopneas, APAP devices may well overestimate the $P_{\text {eff }}$.
Secondly, PLM could induce irregular breathing patterns because a PLM may be accompanied by mild hyperventilation (especially if it is associated with an arousal), which can make normal ventilation between successive PLM difficult to distinguish from hypopneas. Expert technicians may have difficulty distinguishing between mild hypopnea and PLM in some cases [37, 38] (figure 1), and bursts of hyperventilation from PLM some-

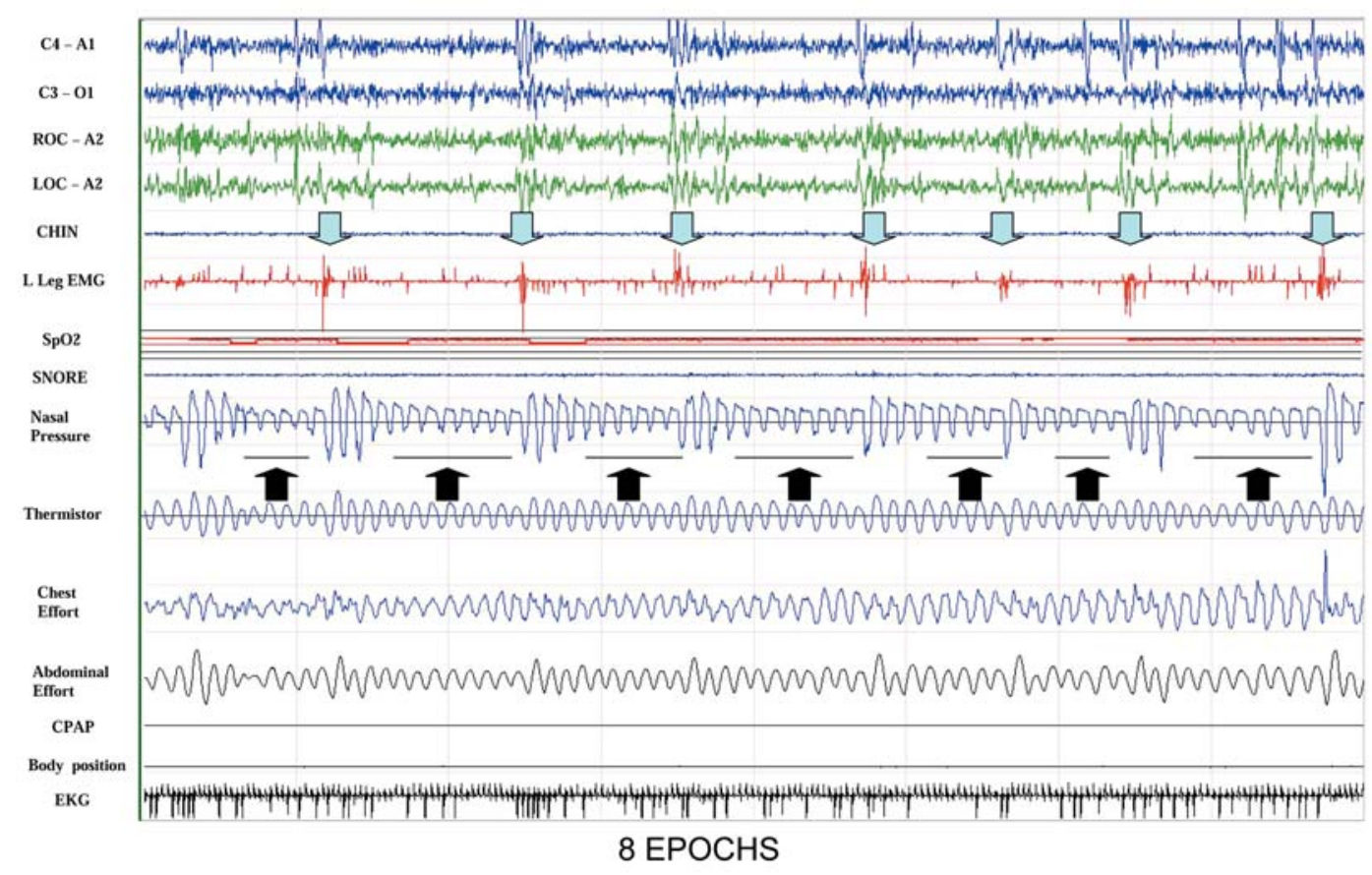

Fig. 1. - Grey arrow: PLM. Black arrows: PLM "pseudohypopnea". Bursts of hyperventilation caused by PLM and arousals make ventilation between bursts resemble hypopnea.

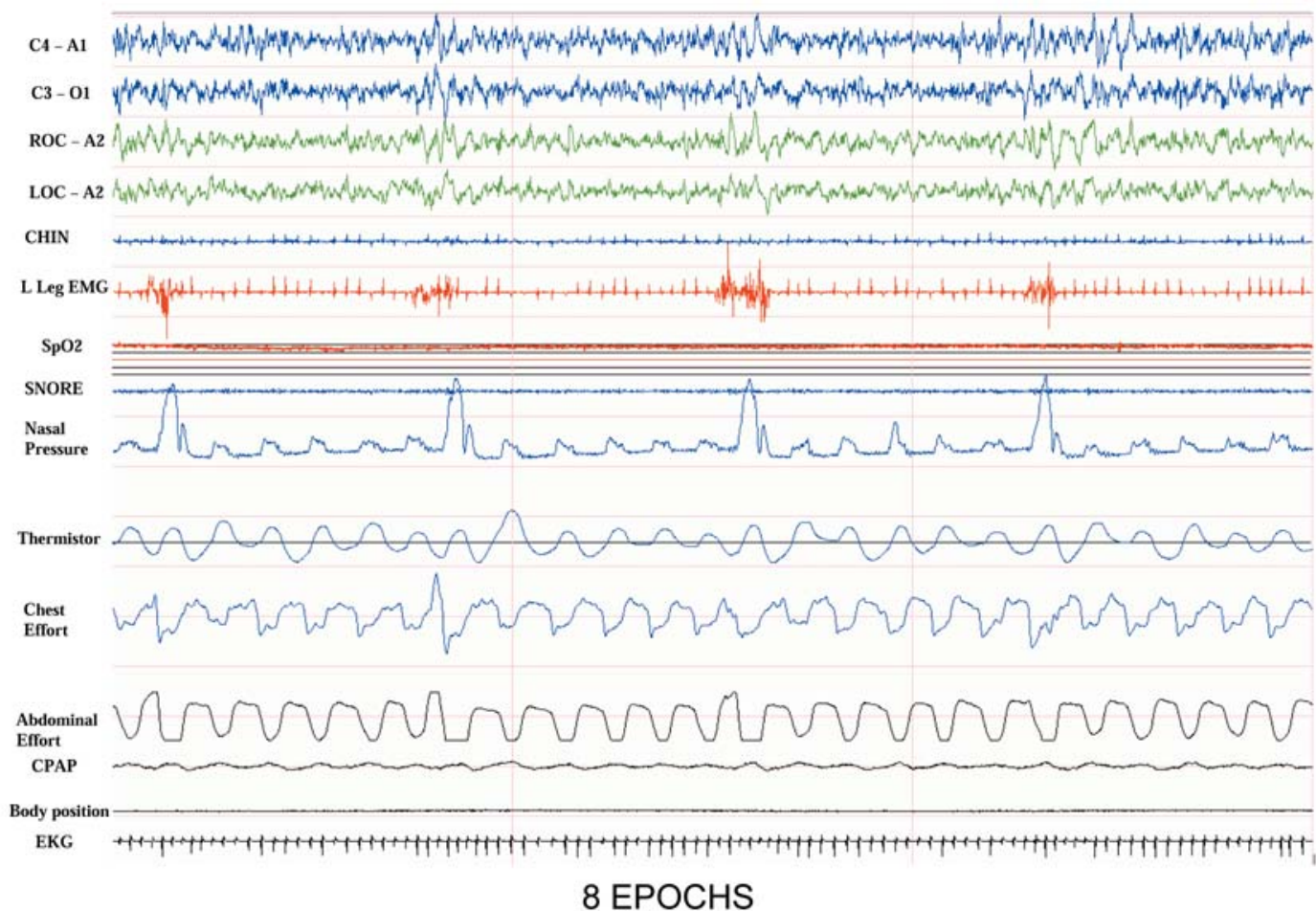

Fig. 2. - PLM increase ventilation during CPAP. 


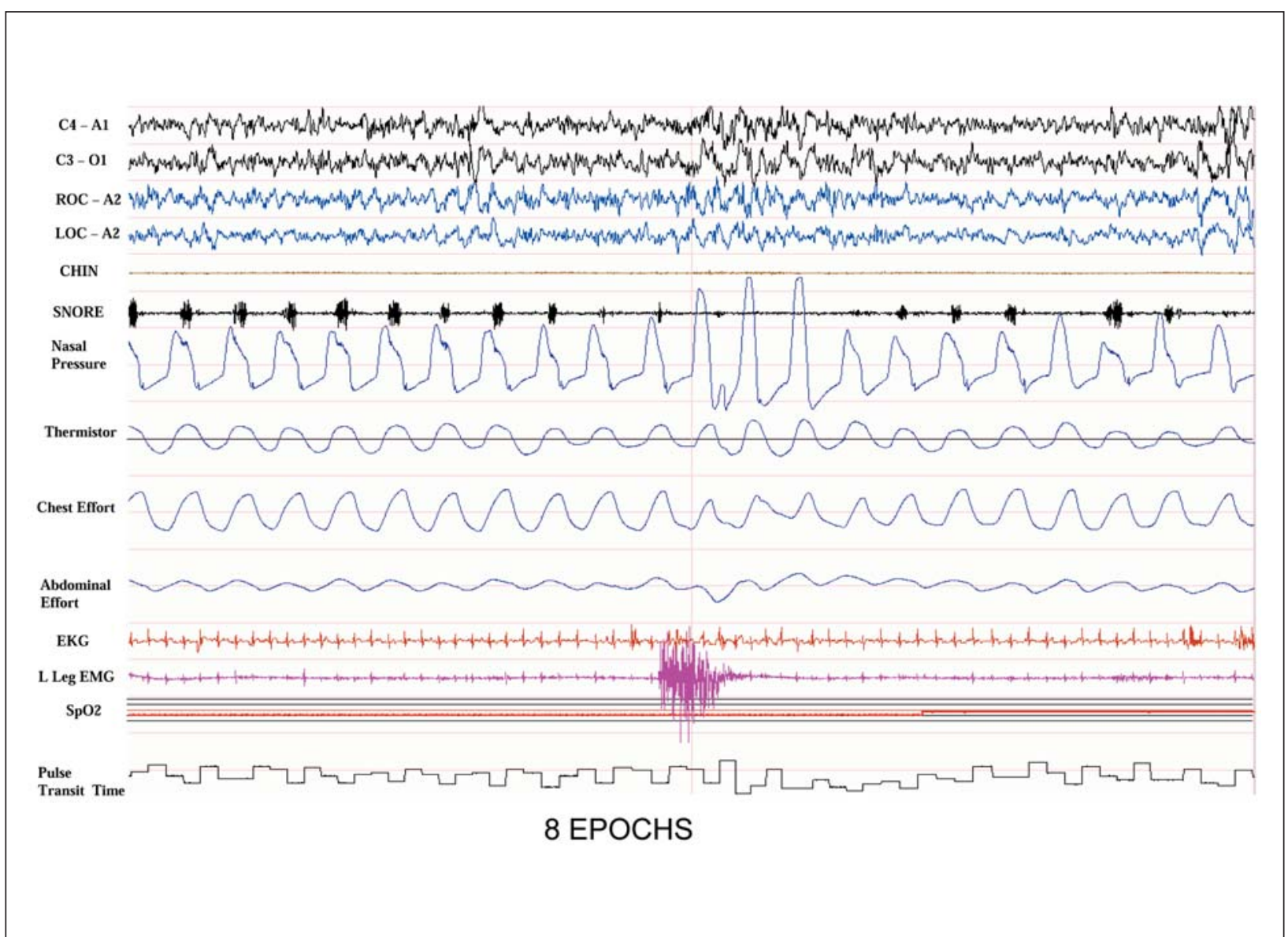

Fig. 3. - A run of flow limitations interrupted by PLM and arousal.

times persist during CPAP (figure 2). Inspiratory flow limitations can also disappear during PLMassociated hyperventilation (figure 3 ). Such abnormal breathing patterns unrelated to any obstructive events could influence APAP pressure due to a misinterpretation of hypopnea and flow limitation, i.e. APAP could read pseudohypopneas as hypopneas and inappropriately raise the pressure. Alternatively, if PLM "cyclically" overcomes any flow limitation, APAP may be unable to detect "runs" of flow limitation and thus fail to increase the pressure accordingly.

Many of the patients in our study had PLM that were not simply associated with respiratory events, because the PLMI and PLMaI changed less during CPAP than the AHI and RESPaI (table 1), suggesting that PLM persisted in some patients independently of any apneas and hypopneas. Our results suggest, however, that the $\mathrm{P}_{\text {eff }}$ was appropriate in most patients despite any underlying PLM and that, on the whole, PLM were not responsible for APAP titration failure.

We conclude that, in selected symptomatic OSAS patients, a single night of partially attended APAP titration in a conventional hospital room enables the optimal fixed pressure for CPAP home therapy to be established in at least $90 \%$ of patients, notwithstanding PLM and a wide range of AHI. The frequent requests for nurses to intervene suggest that a hospital setting is best for the first night of APAP use.

\section{References}

1. Young T, Palta M, Dempsey J, Skatrud J, Weber S, Badr S. The occurrence of sleep disordered breathing among middle aged adults. $N$ Engl J Med 1993; 328: 1230-5.

2. Sullivan CE, Issa FG, Berthon Jones M, Eves L. Reversal of obstructive sleep apnea by continuous positive airway pressure applied to the nares. Lancet 1981; 1 : 862-5.

3. Loube DI, Gay PC, Strohl KP, Pack AI, White DP, Collop NA. Indications for positive airway pressure treatment for adult obstructive sleep apnea patients: a consensus statement. Chest 1999; 115: 863-6.

4. ATS statement. Indications and standards for use of nasal continuous positive airway pressure (CPAP) in sleep apnea syndromes. Am J Respir Crit Care Med 1994; 150: 1738-45.

5. American Sleep Disorder Association. Practice parameters for the indications for polysomnography and related procedures. Sleep 1997; 20: 406.

6. Miljeteig H, Hoffestein V. Determinants of continuous positive airways pressure level for treatment of obstructive sleep apnea. Am Rev Respir Dis 1993; 147: 1526.

7. Coppola MP, Lawee M. Management of obstructive sleep apnea syndrome in the home: the role of portable recording. Chest 1993; 104: 19.

8. Ferber R, Millman R, Coppola M, Fleetham J, Murray $\mathrm{CF}$, Iber C. Portable recording in the assessment of obstructive sleep apnea. Sleep 1994; 17: 378.

9. Roux F, Hilbert J. Continuous positive airway pressure: new generations. Clin Chest Med 2003; 24: 315-342.

10. Berry R, Parish JM, Hartse KM. The use of auto-titrating continuous positive airway pressure for treatment 
of adult obstructive sleep apnea. Sleep 2002; 25: 148159.

11. Fletcher EC, Stich J, Yang KL. Unattended home diagnosis and treatment of obstructive sleep apnea without polysomnography. Arch Fam Med 2000; 9: 168.

12. Lloberes P, Ballester E, Montserrat JM, et al. Comparison of manual and automatic CPAP titration in patients with sleep apnea/hypopnea syndrome. Am J Respir Crit Care Med 1996; 154: 1755-1758.

13. Kessler R, Weitzemblum E, Chaouat A, Iamandi C, Alliotte T. Evaluation of unattended automated titration to determine therapeutic continuous positive airway pressure in patients with obstructive sleep apnea. Chest 2003; 123: 704-710.

14. Condos R, Norman RG, Krishnasamy I, Peduzzi N, Goldring RM, Rapoport D. Flow limitation as a non invasive assessment of residual upper airway resistance during continuous positive airway pressure therapy of obstructive sleep apnea. Am J Respir Crit Care Med 1994; 150: 475-480.

15. Rechtschaffen A, Kales A. A manual of standardized terminology, techniques, and scoring system for sleep stages of human subjects. Los Angeles, CA: Brain Information Service/Brain Research Institute, UCLA, 1968.

16. Ballester E, Badia JR, Hernandez R, Farrè R, Navajas $\mathrm{D}$, Montserrat JM. Nasal prongs in the detection of sleep-related disordered breathing in the sleep apnoea/hypopnoea syndrome. Eur Respir J 1998; 11: 880883.

17. Montserrat JM, Farrè R, Ballester M, Felez A, Pasto M, Navajas D. Evaluation of nasal prongs for estimating nasal flow. Am J Respir Crit Care Med 1997; 155: 211215.

18. Davila DG, Richards KC, Marshall BL, et al. Oximeter acquisition parameter influences the profile of respiratory disturbances. Sleep 2003; 26: 91-94.

19. American Academy of Sleep Medicine task force report. Sleep related breathing disorders in adults: recommendations for syndrome definition and measurement techniques in clinical research. Sleep 1999; 22: 667-689.

20. Sleep Disorders Atlas Task Force of the American Sleep Disorder Association. EEG arousals: scoring rules and examples. Sleep 1992; 15: 174-184.

21. Thomas RJ. Arousals in sleep-disordered breathing: pattern and implications. Sleep 2003; 26: 1042-1047.

22. Stradling JR, Barbour C, Pitson DJ, Davies RJO. Automatic nasal continuous positive airway pressure titration in the laboratory: patient outcome. Thorax 1997, 52: $72-75$.

23. Teschler H, Wessendorf TE, Farhat AA, Konietzko N, Berthon-Jones M. Two months auto-adjusting versus conventional nCPAP for obstructive sleep apnea syndrome. Eur Respir J 2000; 15: 990-995.

24. Teschler H, Berthon Jones M, et al. Automated continuous positive airway pressure titration for obstructive sleep apnea syndrome. Am J Respir Crit Care Med 1996; 154: 734-740.

25. Masa JF, Jimenez A, Duran J, et al. Alternative methods of titrating continuous positive airway pressure: a large multicenter study. Am J Respir Crit Care Med 2004; 170: 1218-1224.

26. Stammnitz A, Jerrentrup A, Penzel T, Peter JH, Vogelmeier C, Becker HF. Automatic CPAP titration with different self-setting devices in patients with obstructive sleep apnea. Eur Respir J 2004; 24: 273-278.

27. Berkani M, Lofaso F, Chouaid C, et al. CPAP titration by an auto - CPAP device based on snoring detection: a clinical trial and economic consideration. Eur Respir $J$ 1998; 12: 759-63.

28. Gagnadoux F, Rakotonanhary D, Martins de Araujo MT, et al. Long term efficacy of fixed CPAP recommended by Autoset for OSAS. Sleep 1999; 22: 10951097.

29. Series F. Accuracy of unattended home CPAP titration in the treatment of obstructive sleep apnea. Am J Respir Crit Care Med 2000; 162: 94-97.

30. Badia JB, Farre R, Kimoff RJ, et al. Clinical application of the forced oscillation technique for CPAP titration in the sleep apnea-hypopnea syndrome. Am J Respir Crit Care Med 1999, 160: 1550-1554.

31. Marrone O, Insalaco G, Bonsignore MR, Romano S, Salvaggio A, Bonsignore G. Sleep correlates of continuous positive airway pressure variations during application of an autotitrating continuous positive airway pressure machine in patients with obstructive sleep apnea syndrome. Chest 2002; 121: 759-767.

32. Lofaso F, Lerou K, Quera S, Mroue G, Dortho MP, Isabey D. Snoring detection during autonasal continuous positive airway pressure. Eur Respir J 2002; 19: 108-111.

33. Thomas RJ, Terzano MG, Parrino L, Weiss W. Obstructive sleep disordered breathing with a dominant cyclic alternating pattern. A recognizable polysomnographic variant with practical clinical implications. Sleep 2004; 27: 229-234.

34. Yamashiro Y, Kryeger M. Acute effect of nasal CPAP on periodic limb movements associated with breathing disorders during sleep. Sleep 1994; 17: 172-175.

35. Baran AS, Richert AC, Douglass AB, May W, Ansarin $\mathrm{K}$. Change in periodic limb movement index during treatment of obstructive sleep apnea with continuous positive airway pressure. Sleep 2003; 26: 717-720.

36. American Sleep Disorders Association. International classification of sleep disorders, revised: diagnostic and coding manual. American Sleep Disorder Association, Rochester. MN, 1997.

37. Chervin R. Periodic leg movements and sleepiness in patients evaluated for sleep disordered breathing. Am J Respir Crit Care Med 2001; 164: 1454-1458.

38. Sthoos RA, Blum HC, Suh BY, Guillelminault C. Misinterpretation of sleep breathing disorder by periodic limb movement disorder. Sleep Breath 2001; 5: 131-137. 